\title{
Coping up with the Information Overload in the Medical Profession
}

\author{
Ajit Kumar' ${ }^{1}$, Sanjeev Maskara ${ }^{2}$ \\ ${ }^{1}$ Goa Institute of Management, Ribandar, India \\ ${ }^{2}$ The Practice PLC, Amersham, UK \\ Email: ajitmaskara@gmail.com, sanjeevmaskara@gmail.com
}

Received 4 November 2015; accepted 23 November 2015; published 26 November 2015

Copyright (C) 2015 by authors and Scientific Research Publishing Inc.

This work is licensed under the Creative Commons Attribution International License (CC BY). http://creativecommons.org/licenses/by/4.0/

c) (i) Open Access

\begin{abstract}
The recent technological advancement has proved to be tremendously helpful for medical consultants. However, this advancement has also generated an enormous volume and variety of data, with a high velocity causing an information load for the medical consultants. Information overload can be defined as a difficulty a person can have in comprehending issue and making judgments that are caused by the presence of too much information. Information overload occurs when the amount of input to a system surpasses its processing capability. Decision-makers have a limited cognitive processing ability. Consequently, when information overload happens, it is possible that a decline in decision quality will take place. Decision-makers, such as medical consultants, have fairly limited cognitive processing capacity. Consequently, when information overload occurs, it is likely that a reduction in decision quality will occur. The aim of this study is to assess the impact of information overload on medical consultants' life, its causes, and potential ways to deal with it. We performed a literature review to find the effects of information overload on medical consultants. Twelve research papers were considered for thematic analysis using NVivo 10 tool. These papers revealed four themes: 1) traditional methods of data collection; 2) modern ways of data collection; 3) consequences of modern ways of data collection; and 4) the need for handling information overload. This study suggests the development of a Continuing Professional Development course that explains how to deal with information overload, and availing the same through E-Learning mode might be one immediate solution.
\end{abstract}

\section{Keywords}

Information Overload, E-Learning, Continuous Professional Development, Medical Consultant

\section{Introduction}

The recent technological advancement, particularly the Internet, has proven to be tremendously helpful for med- 
ical consultants to deal with patient care related data, healthcare information, and knowledge, thereby facilitating quality health care for their clients. However, this advancement has also generated an enormous volume and variety of data, with a high velocity. Changing nature of work with the emphasis on interdisciplinary and collaborative work contributed to the information repository causing an extra information load for the medical consultants. Information overload can be defined as a difficulty a person can have in comprehending issue and making judgments that are caused by the presence of too much information. Information overload occurs when the amount of input to a system surpasses its processing capability. Decision-makers have a limited cognitive processing ability. Consequently, when information overload happens, it is possible that a decline in decision quality will take place. Decision-makers, such as medical consultants, have fairly limited cognitive processing capacity. Consequently, when information overload occurs, it is likely that a reduction in decision quality will occur. Some factors associated with medical consultants, such as lack of time to search, forgetfulness, belief, and concerns about the relationship with the patient could have some adverse effects on the use of this vast knowledge base [1] [2]. A wide variation among consultants can be seen about the factors that cause variation in information seeking behavior [3]. The wide variation in knowledge seeking activities of medical consultants suggests a need for further categorization of information need and information sources.

The Reuters report identified some of the effects of information overload: time waste, delayed decision making, distraction, and stress. Unfortunately, medical consultants already are suffering from all these. The data explosion increased their suffering further. The information overload on a medical consultant is inevitable due to technological advancement, diverse and growing amounts of available information, and changing nature of work with the new emphasis on interdisciplinary and collaborative work that requires more communication. It has been commonly accepted that information overload weakens the effectiveness of consultants. This information anarchy, such as information overload, underload, scatter, conflict, and error is experienced routinely by medical consultants [4]. All this chaos is not only inconvenient, annoying, and frustrating, but also has implications for medical consultant's performance and patient safety [4]. The information overload issues need to be seriously taken if we wish that the medical consultants should get the right information, at the right time, and at the point of care. Therefore, we argue that we need a solid plan to keep medical consultants up to date. The aim of this study is to assess the impact of information overload on medical consultants' life, its causes, and potential ways to deal with it.

\section{Methods}

We performed a literature review to find the impact of information overload on medical consultants. We conducted an exhaustive search using keywords and their combination, such as "clinician", "information overload", "medical consultant", and "physician". A literature search was carried out on a variety of databases, such as Web of Science, PubMed, Google Scholar, and Scopus from 2000 to 2014. We identified twenty-one research papers. Out of twenty-one, we excluded nine papers that did not meet our criteria. We considered remaining twelve research papers for this study [1] [2] [4]-[13]. We imported the PDF files of twelve papers using EndNote X6 tool (a reference manager) including their complete references. Afterward, we imported all these PDF files into another qualitative data analysis tool called NVivo 10. All papers were analyzed and coded (concepts) using NVivo 10 tools. Thematic analysis was used to identify themes and sub-themes under four categories that can be seen in the Results section. The basic idea of the thematic analysis is to read and re-read the corpus (here PDF file of twelve papers), code them; and then, combine codes into overarching themes and sub-theme that accurately depict the data.

\section{Results}

The thematic analysis of twelve papers revealed four themes and corresponding sub-themes as shown in Table 1.

\section{Discussion}

As can be seen in Table 1, the first theme advocates about the traditional ways of data. In traditional ways, data collection was a difficult task, and it involved a good amount of money and effort. Therefore, we used to select variables very carefully and collect data on the well-chosen variable. On the other hand, as indicated in the second theme (Table 1), we can easily record observations with larger numbers of variables using automatic 
Table 1. Themes and sub-themes identified from thematic analysis.

\begin{tabular}{ll}
\hline Themes & Sub-themes \\
\hline 1) Traditional methods of data collection & $\begin{array}{l}\text { a. Well-chosen variable } \\
\text { b. Manual data collection }\end{array}$ \\
& $\begin{array}{l}\text { a. Recording more observations with larger numbers of variables (Big Data) using automatic } \\
\text { devices } \\
\text { b. Growth of huge repositories, such as PubMed } \\
\text { 2) Modern ways of data collection }\end{array}$ \\
$\begin{array}{ll}\text { c. High speed of data gathering from variety of data sources, such as Electronic Health Record, } \\
\text { d) Consequence of information }\end{array}$ \\
$\begin{array}{ll}\text { a. The information of high relevance gets lost amidst big data generated and poses challenges for } \\
\text { medical consultants } \\
\text { b. Veracity (biases, noise, and abnormality in data), } \\
\text { c. Validity (data accuracy for the intended usage), and } \\
\text { d. Volatility (duration of data storage) }\end{array}$ \\
$\begin{array}{ll}\text { 4) Need for handling information } \\
\text { overload }\end{array}$ \\
$\begin{array}{l}\text { b. E-Learning mode of training } \\
\text { c. Use of knowledge mining tools to deal with information overload, such as using WaX, } \\
\text { decision-support, and so on }\end{array}$
\end{tabular}

devices at a very low-cost and effort. Many huge repositories such as PubMed have emerged. Moreover, the velocity of data gathering has gone up tremendously due to the availability of a variety of data capturing devices, such as electronic health record, imaging modalities, and medical devices. The third theme indicates that the information of high relevance gets lost amidst big data generated and poses challenges for medical consultants. Medical consultants are facing issues such as veracity (biases, noise, and abnormality in data), validity (data accuracy for the intended usage), and volatility (duration of data storage). The fourth theme points to develop Continuing Professional Development course that explains how to deal with information overload and facilitate the same using E-Learning to the medical consultants. Also, consultants can be trained in tools, such as WaX system and decision support system to deal with the information overload [14].

\section{Conclusion}

The information overload on the medical consultants is inevitable due to technological advancement. Healthcare consultants typically do not have time; however, their knowledge needs to be continuously updated. Moreover, they should get the right information, at the right time, at the point of care. The recent information explosion has caused several difficulties in their professional life. Therefore, the information overload issues need to be taken seriously. One immediate solution to address information overload could be the development of Continuing Professional Development (CPD) course materials, which teaches medical consultants how to deal with information overload. Also, this CPD course could be availed through E-Learning because of time constraints with the medical professionals.

\section{References}

[1] Hall, A. and Walton, G. (2004) Information Overload within the Health Care System: A Literature Review. Health Information \& Libraries Journal, 21, 102-108. http://dx.doi.org/10.1111/j.1471-1842.2004.00506.x

[2] Bawden, D. and Robinson, L. (2009) The Dark Side of Information: Overload, Anxiety and Other Paradoxes and Pathologies. Journal of Information Science, 35, 180-191. http://dx.doi.org/10.1177/0165551508095781

[3] Dawes, M. and Sampson, U. (2003) Knowledge Management in Clinical Practice: A Systematic Review of Information Seeking Behavior in Physicians. International Journal of Medical Informatics, 71, 9-15. http://dx.doi.org/10.1016/S1386-5056(03)00023-6

[4] Beasley, J.W., Wetterneck, T.B., Temte, J., Lapin, J.A., Smith, P., Rivera-Rodriguez, A.J. and Karsh, B.T. (2011) Information Chaos in Primary Care: Implications for Physician Performance and Patient Safety. The Journal of the American Board of Family Medicine, 24, 745-751. http://dx.doi.org/10.3122/jabfm.2011.06.100255

[5] Hanka, R. and Fuka, K. (2000) Information Overload and “Just-in-Time” Knowledge. The Electronic Library, 18, 279285. http://dx.doi.org/10.1108/02640470010346021

[6] De Lusignan, S., Lakhani, M. and Chan, T. (2003) The Role of Informatics in Continuing Professional Development 
and Quality Improvement in Primary Care. Journal of Postgraduate Medicine, 49, 163.

[7] Davies, K. (2007) The Information-Seeking Behavior of Doctors: A Review of the Evidence. Health Information \& Libraries Journal, 24, 78-94. http://dx.doi.org/10.1111/j.1471-1842.2007.00713.x

[8] Smith, R. (2010) Strategies for Coping with Information Overload. BMJ, 341, c7126. http://dx.doi.org/10.1136/bmj.c7126

[9] Holzinger, A., Geierhofer, R. and Errath, M. (2007) Semantic Information in Medical Information Systems from Data and Information to Knowledge: Facing Information Overload. Proceedings of I-MEDIA, 7, 323-330.

[10] Hunt, R.E. and Newman, R.G. (1997) Medical Knowledge Overload: A Disturbing Trend for Physicians. Health Care Management Review, 22, 70-75. http://dx.doi.org/10.1097/00004010-199724000-00009

[11] Underhill, J. and Pegler, S. (2005) Dealing with Information Overload: Application of Evidence at Point of Care. Pharmaceutical Journal, 274.

[12] Davis, D., O’Brien, M.A.T., Freemantle, N., Wolf, F.M., Mazmanian, P. and Taylor-Vaisey, A. (1999) Impact of Formal Continuing Medical Education: Do Conferences, Workshops, Rounds, and Other Traditional Continuing Education Activities Change Physician Behavior or Health Care Outcomes? JAMA, 28, 867-874. http://dx.doi.org/10.1001/jama.282.9.867

[13] Achike, F.I. and Ogle, C.W. (2000) Information Overload in the Teaching of Pharmacology. The Journal of Clinical Pharmacology, 40, 177-183. http://dx.doi.org/10.1177/00912700022008838

[14] Hanka, R., O’Brien, C., Heathfield, H. and Buchan, I. (1999) WAX Active Library; a Tool to Manage Information Overload. Topics in Health Information Management, 20, 69-82. 